\title{
Solubility of Anthracene in Ternary 1,4-Dioxane + Alcohol + Cyclohexane Solvent Mixtures at 298.15 K
}

\author{
Karen J . Pribyla, Michael A. Spurgin, I vette Chuca, and William E. Acree, J r.* \\ Department of Chemistry, University of North Texas, Denton, Texas 76203-5070
}

\begin{abstract}
Experimental solubilities are reported for anthracene dissolved in ternary 1,4-dioxane + 1-propanol + cyclohexane, 1,4-dioxane + 2-propanol + cyclohexane, 1,4-dioxane + 1-butanol + cyclohexane, 1,4-dioxane +2 -butanol + cyclohexane, and 1,4-dioxane +2 -methyl-1-propanol + cyclohexane solvent mixtures at $25^{\circ} \mathrm{C}$ and atmospheric pressure. Nineteen compositions were studied for each of the five solvent systems. Results of these measurements are used to test the predictive ability of the ternary solvent form of the combined NIMS/Redlich-Kister equation. Computations showed that the model predicted the observed mole fraction solubilities to within an overall average absolute deviation of about $4.7 \%$.
\end{abstract}

\section{Introduction}

Solid-liquid equilibrium data of organic nonelectrolyte systems are becoming increasingly important in the petroleum industry, particularly in light of present trends toward heavier feedstocks and the known carcinogenicity/ mutagenicity of many of the larger polycyclic aromatic compounds. Solubility data for a number of polycyclic aromatic hydrocarbons (i.e., anthracene and pyrene) and heteroatom polynuclear aromatics (i.e., carbazole, dibenzothiophene, and xanthene) have been published in the recent chemical literature. For a listing of references see Acree. ${ }^{1-3}$ Despite efforts by experimentalists and scientific organizations, both in terms of new experimental measurements and critically evaluated data compilations, there still exist numerous systems for which solubility data are not readily available.

In the present study, anthracene solubilities have been measured in the five ternary 1,4-dioxane + alcohol + cyclohexane systems at $(25.0 \pm 0.1){ }^{\circ} \mathrm{C}$. Nineteen ternary compositions were studied for each of the five systems. Results of these measurements are used to test the predictive ability of expressions based upon the general mixing model used in deriving the combined NIMS/ Redlich-Kister equation.

\section{Experimental Methods}

Anthracene (Aldrich, 99.9+\%) was used as received. 1-Propanol (Aldrich, 99+\%, anhydrous), 2-propanol (Aldrich, 99+\%, anhydrous), 1-butanol (Aldrich, HPLC, 99.8+\%), 2-butanol (Aldrich, 99+\%, anhydrous), 2-methyl1-propanol (Aldrich, 99.5\%, anhydrous), cyclohexane (Aldrich, HPLC, 99.9+\%), and 1,4-dioxane (Aldrich, $99.8 \%$, anhydrous) were stored over molecular sieves and distilled shortly before use. Gas chromatographic analysis showed solvent purities to be 99.7 mole percent or better. Ternary solvent mixtures were prepared by mass so that compositions could be calculated to within 0.0001 mole fraction. Excess solute and solvent were equilibrated in

* To whom correspondence should be addressed. E-mail, acree@unt.edu; fax, (940) 565-4318. sealed amber glass bottles in a constant temperature bath at $(25.0 \pm 0.1){ }^{\circ} \mathrm{C}$ for at least 3 days. Aliquots of the saturated anthracene solutions were transferred into a tared volumetric flask to determine the amount of sample, and diluted quantitatively with methanol for spectroscopic analysis at $356 \mathrm{~nm}$. A more detailed description of the methods of sample equilibration and spectrophotometric analysis is presented in an earlier paper. ${ }^{4}$ Experimental anthracene solubilities in the five 1,4-dioxane + alcohol + cyclohexane solvent mixtures are listed in Table 1. Numerical values represent the average of between four and eight independent determinations; the measured values are reproducible to within $\pm 1.5 \%$.

\section{Results and Discussion}

Acree and co-workers ${ }^{5-7}$ suggested the combined NIBS/ Redlich-Kister equation for the mathematical representation of isothermal solubility data in binary solvent systems:

$$
\begin{aligned}
\ln x_{A}^{\text {sat }}=x_{B}{ }^{0} \ln \left(x_{A}{ }^{\text {sat }}\right)_{B}+x_{C}{ }^{0} \ln \left(x_{A}{ }^{\text {sat }}\right)_{C}+ \\
x_{B}{ }^{o} x_{C}{ }^{o} \sum_{i=0}^{N} S_{i}\left(x_{B}{ }^{0}-x_{C}{ }^{0}\right)^{i}
\end{aligned}
$$

where $\mathrm{x}_{\mathrm{B}}{ }^{\circ}$ and $\mathrm{x}_{C}{ }^{\circ}$ refer to the initial mole fraction composition of the binary solvent calculated as if the solute were not present, and $\left(\mathrm{x}_{\mathrm{A}}{ }^{\mathrm{sat}}\right)_{\mathrm{i}}$ denotes the measured solute solubility in pure solvent $i$. The various $S_{i}$ curve-fit parameters can be evaluated using a least-squares analysis. Though originally suggested as an empirical mathematical representation, eq 1 has been derived from the two-body and three-body interaction thermodynamic mixing model proposed by $\mathrm{H}$ wang et al.5,8 and from the nearly ideal binary Solvent (NIBS) model ${ }^{9-12}$ by replacing the solvent unmixing term (i.e., the $\triangle G_{B C}{ }^{E}$ term) with a Redlich-Kister mathematical representation. The NIBS model requires knowledge of the excess Gibbs energy, $\triangle G_{B C}{ }^{E}$, of the binary solvent mixture. The required $\triangle G_{B C}{ }^{E}$ values are determined from experimental binary vapor-liquid equilibria (VLE) data, which is often reported in the chemical engineering literature in the form of a Redlich-Kister mathematical representation. 
Table 1. Experimental Mole Fraction Solubilities of Anthracene ( $x_{A}$ sat) in Ternary 1,4-Dioxane (B) + Alcohol (C) + Cyclohexane (D) Solvent Mixtures at 298.15 K

\begin{tabular}{|c|c|c|c|c|c|}
\hline$X_{B}{ }^{\circ}$ & $x_{C}{ }^{0}$ & $\mathrm{X}_{\mathrm{A}}$ sat & $X_{B}{ }^{0}$ & $x_{C}{ }^{0}$ & $x_{A}{ }^{\text {sat }}$ \\
\hline \multicolumn{6}{|c|}{ 1,4-Dioxane (B) + 1-Propanol (C) + Cyclohexane (D) } \\
\hline 0.3419 & 0.3906 & 0.003921 & 0.1771 & 0.2058 & 0.003079 \\
\hline 0.1437 & .7402 & 0.001604 & 0.6976 & 0.1803 & 0.006711 \\
\hline 0.2742 & 0.3107 & 0.003625 & 0.5025 & 0.29 & 0.005290 \\
\hline 0.2542 & 0.5457 & & & & 0.002502 \\
\hline 0.7091 & 0.124 & 0.007311 & 0.1043 & & 0.001443 \\
\hline 0.6853 & 0.229 & 0.006388 & & & \\
\hline 0.188 & 0.73 & 01845 & & & \\
\hline & 0.5739 & 0.001 & 0.4377 & & \\
\hline & & & 0.5291 & 0.1354 & \\
\hline 0.4784 & 0.4381 & 0.004384 & & & \\
\hline \multicolumn{6}{|c|}{ 1,4-Dioxane (B) + 2-Propanol (C) + Cyclohexane (D) } \\
\hline 0.3454 & 0.3819 & 0.003745 & & & 0.003121 \\
\hline & .7289 & & & & \\
\hline 0.2 & 0.3062 & & & & 5073 \\
\hline & 0.5579 & & & & \\
\hline & & & & & \\
\hline & & & & & \\
\hline & & & & & \\
\hline & & & & & 5403 \\
\hline & & & 0.5309 & 0.1327 & \\
\hline & & & & & \\
\hline \multicolumn{6}{|c|}{ 1,4-Dioxane (B) + 1-Butanol (C) + Cyclohexane (D) } \\
\hline 0.3714 & & & & & \\
\hline 0.172 & & & & & \\
\hline & & & & & \\
\hline & & & & & \\
\hline & & & & & \\
\hline & & & & & \\
\hline & & & & & \\
\hline & & & & & \\
\hline & & & 0.5417 & 0.1124 & 0.006553 \\
\hline & & & & & \\
\hline \multicolumn{6}{|c|}{ 1,4-Dioxane (B) + 2-Butanol (C) + Cyclohexane (D) } \\
\hline 0.3227 & 0.4227 & & 0.1827 & 0.1763 & 0.003137 \\
\hline & & & & & \\
\hline & & & & & \\
\hline & & & & & \\
\hline & & & & & \\
\hline & & & & & \\
\hline & & & & & \\
\hline & & & & & \\
\hline 0.42 & 0.48 & 0.00 & 0.5420 & 0.1115 & 0.006332 \\
\hline 0.5181 & 0.3865 & 0.004627 & & & \\
\hline \multicolumn{6}{|c|}{ 1,4-Dioxane (B) + 2-M ethyl-1-propanol (C) + Cyclohexane (D) } \\
\hline & & & & & \\
\hline & & & & & \\
\hline & & & & & 5275 \\
\hline 0.2805 & 0.5009 & & & 0.2 & \\
\hline 0.7276 & 0.1055 & 0.0072 & 0.1224 & 0.70 & 0.001382 \\
\hline 0.7153 & & & & & \\
\hline & & & & & \\
\hline 0.1277 & & & & & \\
\hline 0.4243 & 0.4828 & 0.003416 & 0.5388 & 0.1185 & 0.006045 \\
\hline & & & & & \\
\hline
\end{tabular}

F or a ternary solvent system, the mathematical representation takes the form of

$$
\begin{aligned}
& \ln x_{A}^{\text {sat }}=x_{B}{ }^{\circ} \ln \left(x_{A}{ }^{\text {sat }}\right)_{B}+x_{C}{ }^{o} \ln \left(x_{A}{ }^{\text {sat }}\right)_{C}+x_{D}{ }^{0} \ln \left(x_{A}{ }^{\text {sat }}\right)_{D}+ \\
& x_{B}{ }^{o} x_{C}{ }^{o} \sum_{i=0}^{r} S_{i, B C}\left(x_{B}{ }^{o}-x_{C}{ }^{0}\right)^{i}+x_{B}{ }^{o} x_{D}{ }^{o} \sum_{j=0}^{S} S_{j, B D}\left(x_{B}{ }^{o}-x_{D}{ }^{0 j}+\right. \\
& x_{C}^{o} x_{D}^{o} \sum_{k=0}^{t} S_{k, C D}\left(x_{C}^{o}-x_{D}\right)^{k}
\end{aligned}
$$

Equation 2 is referred to as the combined NIMS/RedlichKister equation. Recent studies have shown that eq 2 provides reasonably accurate predictions for anthracene
Table 2. Summarized Comparison Between Observed Anthracene Solubilities in Ternary 1,4-Dioxane + Alcohol + Cyclohexane Solvent Mixtures and Predicted Values Based upon the Combined NIMS/Redlich-Kister Eq 2

\begin{tabular}{lc}
\hline ternary solvent mixture & \% deva \\
\hline 1,4-dioxane (B) + 1-propanol (C) + cyclohexane (D) & 5.1 \\
1,4-dioxane (B) + 2-propanol (C) + cyclohexane (D) & 4.6 \\
1,4-dioxane (B) + 1-butanol (C) + cyclohexane (D) & 5.4 \\
1,4-dioxane (B) + 2-butanol (C) + cyclohexane (D) & 4.2 \\
1,4-dioxane (B) + 2-methyl-1-propanol (C) + & 4.0 \\
cyclohexane (D) &
\end{tabular}

a Deviation $(\%)=(100 / N) \sum \mid\left[\left(x_{A}\right.\right.$ sat $)$ calc $-\left(x_{A}\right.$ sat $\left.) \exp \right] /\left(x_{A}\right.$ sat $) \exp \mid$, where $\mathrm{N}$ corresponds to the number of data points for each ternary system. In the present study, solubilities were determined at 19 different ternary solvent compositions.

Table 3. Combined NIBS/Redlich-Kister Parameters Calculated from Anthracene Solubilities in the Sub-Binary Solvent Systems

\begin{tabular}{cr}
\hline solvent (B) + solvent (C) & \multicolumn{1}{c}{$\mathrm{S}^{\mathrm{a}}$} \\
\hline 2-methyl-1-propanol (B) + cyclohexane (C) & 1.116 \\
& -0.172 \\
2-propanol (B) + cyclohexane (C) & 0.341 \\
& 1.589 \\
2-butanol (B) + cyclohexane (C) & 0.143 \\
& 0.248 \\
1-propanol (B) + cyclohexane (C) & 1.260 \\
& -0.206 \\
1-butanol (B) + cyclohexane (C) & 1.121 \\
& -0.040 \\
& 0.256 \\
1,4-dioxane (B) + 1-propanol (C) & 0.741 \\
& -0.345 \\
& 0.223 \\
1,4-dioxane (B) + 2-propanol (C) & 2.308 \\
& -1.305 \\
& 0.112 \\
1,4-dioxane (B) + 1-butanol (C) & 2.559 \\
& -1.745 \\
& 0.748 \\
1,4-dioxane (B) + 2-butanol (C) & 1.792 \\
& -1.140 \\
1,4-dioxane (B) + 2-methyl-1-propanol (C) & -0.330 \\
& 2.178 \\
1,4-dioxane (B) + cyclohexane (C) & -1.504 \\
& 0.709 \\
& 2.326 \\
& -1.232 \\
& 0.210 \\
& 2.445 \\
& -0.266 \\
& 0.268 \\
& \\
&
\end{tabular}

a Combined NIBS/Redlich-Kister curve-fit parameters are ordered as $\mathrm{S}_{0}, \mathrm{~S}_{1}$, and $\mathrm{S}_{2}$.

solubilities in ternary two al kane + al cohol ${ }^{13,14}$ and alkane + two alcohol ${ }^{15-17}$ solvent mixtures. Such systems exhibit fairly large deviations from solution ideality arising from the self-association of each alcohol cosolvent, and in mixtures containing two alcohol cosolvents from the formation of heterogeneous hydrogen-bonded chains between dissimilar alcohol molecules.

The predictive ability of eq 2 is summarized in Table 2 for anthracene dissolved in the five 1,4-dioxane + alcohol + cyclohexane systems. Unlike the ternary two alkane + alcohol and alkane + two alcohol solvent mixtures studied previously, hydrogen-bond formation is terminated each time an al cohol molecule hydrogen-bonds with 1,4-dioxane. Published papers ${ }^{18-22}$ have reported the calculated $S_{i}$ parameters for anthracene dissolved in 10 of the 11 subbinary solvent systems, as well as the measured mole 
fraction solubilities in 1-propanol ( $\left.x_{A}{ }^{\text {sat }}=0.000591\right)$, 2-propanol $\left(x_{A}\right.$ sat $\left.=0.000411\right)$, 1-butanol $\left(x_{A}^{\text {sat }}=0.000801\right)$, 2-butanol ( $x_{A}$ sat $\left.=0.000585\right), 2$-methyl-1-propanol $\left(x_{A}{ }^{\text {sat }}=\right.$ $0.000470)$, cyclohexane $\left(x_{A}\right.$ sat $\left.=0.001553\right)$, and 1,4-dioxane $\left(\mathrm{x}_{\mathrm{A}}{ }^{\text {sat }}=0.008329\right)$. Solubility data for the 11th binary solvent system were reported several years before the development of the combined NIBS/Redlich-Kister equation. We have determined the numerical values of the $S_{i}$ parameters for the binary 1,4-dioxane + cyclohexane solvent system by curve-fitting the experimental anthracene mole fraction solubility data of Procyk et al.23 in accordance with eq 1 . Numerical values of the $S_{i}$ parameters have been tabulated in Table 3 for convenience. Examination of the numerical entries in Table 3 reveals that eq 2 predicts the solubility of anthracene to within an overall average absolute deviation of $4.7 \%$, which is about 3 times larger than the experimental uncertainty of $\pm 1.5 \%$ in the measured anthracene solubilities.

We note that the difference between predicted and observed values is also larger than the $\pm 2 \%$ error that was observed in our earlier studies involving anthracene dissolved in ternary alkane + alkane + alcohol, 13,14 alkane + alcohol + alcohol, ${ }^{15-17}$ and dibutyl ether + alkane + alcohol mixtures. ${ }^{24-26}$ In all fairness, we should mention that the earlier studies covered much smaller (4- to 8-fold) ranges in anthracene mole fraction solubilities. One should not expect the same level of predictive accuracy in systems that cover significantly larger sol ubility ranges. The five ternary 1,4-dioxane + alcohol + cyclohexane systems studied here cover up to a 20 -fold range in mole fraction solubility. The predictive accuracy of most solution models does decrease both with increasing solution nonideality and with greater dissimilarities between the solute solubility in the pure solvents. The combined NIMS/Redlich-Kister solution model is no different than other solution models ${ }^{9-12}$ in this regard. Unpublished computations ${ }^{27}$ show that the UNIFAC and Modified UNIFAC (Dortmund) group contribution methods predict anthracene solubilities in 1,4-dioxane, cyclohexane, and the five alcohol cosolvents to within an average absolute error of about $20 \%$. We expect that the predictive accuracy of both group contribution methods will be $\pm 20 \%$ or so when applied to anthracene solubilities in the five ternary 1,4-dioxane + alcohol + cyclohexane solvent systems studied here.

\section{Acknowledgment}

I vette Chuca thanks the University of North Texas and the U.S. Department of Education for support provided under the Ronald E. McNair Postbaccalaureate Achievement Program. Michael Spurgin thanks the UNT Texas Academy of Math and Science (TAMS) for an undergraduate summer research fellowship.

\section{Literature Cited}

(1) Acree, W. E., J r. Polycyclic Aromatic Hydrocarbons in Pure and Binary Solvents; IUPAC Solubility Data Series, Vol. 54; Oxford University Press: Oxford, U.K., 1994.

(2) Acree, W. E., J r. Polycyclic Aromatic Hydrocarbons: Binary Nonaqueous Systems: Part 1 (Solutes A-E); IUPAC Solubility Data Series, Vol. 58; Oxford University Press: Oxford, U.K., 1995.

(3) Acree, W. E., J r. Polycyclic Aromatic Hydrocarbons: Binary Nonaqueous Systems: Part 2 (Solutes $\mathrm{F}-\mathrm{Z}$ ); IUPAC Solubility Data Series, Vol. 59; Oxford University Press: Oxford, U.K., 1995

(4) Powell, J. R.; Coym, K. S.; Acree, W. E., J r. Solubility of Anthracene in Binary Alcohol + 2-Methoxyethyl Ether Solvent Mixtures. J . Chem. Eng. Data 1997, 42, 395-397.

(5) Acree, W. E.,J r. Mathematical Representation of Thermodynamic Properties. Part 2. Derivation of the Combined Nearly Ideal Binary Solvent (NIBS)/Redlich-Kister Mathematical Representation from a Two-Body and Three-Body Interactional Mixing Model. Thermochim. Acta 1992, 198, 71-79.
(6) Acree, W. E., J r.; McCargar, J . W.; Zvaigzne, A. I.; Teng, I.-L. Mathematical Representation of Thermodynamic Properties. Carbazole Solubilities in Binary Alkane + Dibutyl Ether and Alkane + Tetrahydropyran Solvent Mixtures. Phys. Chem. Liq. 1991, 23, $27-35$.

(7) Acree, W. E. J r. Zvaigzne, A. I. Thermodynamic Properties of Nonelectrolyte Solutions. Part 4. Estimation and Mathematical Representation of Solute Activity Coefficients and Solubilities in Binary Solvents Using the NIBS and Modified Wilson Equations. Thermochim. Acta 1991, 178, 151-167.

(8) Hwang, C. A.; Holste, J . C.; Hall, K. R.; Mansoori, G. A. A simple relation to predict or to correlate the excess functions of multicomponent mixtures. Fluid Phase Equilib. 1991, 62, 173-189.

(9) Acree, W. E., J r.; Bertrand, G. L. Thermochemical Investigations of Nearly Ideal Binary Solvents. 3. Solubility in Systems of Nonspecific Interactions. J. Phys. Chem. 1977, 81, 1170-1173.

(10) Acree, W. E., J r.; Bertrand, G. L. Thermochemical Investigations of Nearly I deal Binary Solvents. VII. Monomer and Dimer Models for Solubility of Benzoic Acid in Simple Binary and Ternary Solvents. J . Pharm. Sci. 1981, 70, 1033-1036.

(11) Acree, W. E., J r.; Bertrand, G. L. Thermochemical Investigations of Nearly I deal Binary Solvents. VI. Solubilities of I odine and Benzil in Systems of Nonspecific Interactions. J. Solution Chem. 1983, 12, 101-113.

(12) Deng, T.; Horiuchi, S.; De Fina, K. M.; Hernández, C.; Acree, W. E..J $r$. Solubility of Anthracene in Multicomponent Solvent Mixtures Containing Propanol, Butanol, and Alkanes. J . Chem. Eng. Data 1999, 44, 798-802.

(13) Deng, T.; Acree, W. E., J r. Solubility of Anthracene in Ternary Propanol + 2,2,4-Trimethylpentane + Cyclohexane and Butano + 2,2,4-Trimethylpentane + Cyclohexane Solvent Mixtures. J . Chem. Eng. Data 1998, 43, 1059-1061.

(14) Deng, T.; Hernández, C. E.; Roy, L. E.; Acree, W. E., J r. Solubility of Anthracene in Ternary (Propanol + Heptane + Cyclohexane) and (Butanol + Heptane + Cyclohexane) Solvent Mixtures. J . Chem. Thermodyn. 1999, 31, 205-210.

(15) Deng, T.; Childress, S. D.; De Fina, K. M.; Acree, W. E., J r. Solubility of Anthracene in Ternary Propanol + Butanol + Heptane Solvent Mixtures. Chem. Eng. Commun. 1999, 172, 217-224.

(16) Deng, T.; Childress, S. D.; De Fina, K. M.; Sharp, T. L.; Acree, W. E.,J r. Solubility of Anthracene in Ternary Propanol + Butanol $+2,2,4-T r i-m e t h y l p e n t a n e$ Solvent Mixtures. J . Chem. Eng. Data 1998, 43, 1065-1067.

(17) Deng, T.; Acree, W. E., J r. Solubility of Anthracene in Ternary Propanol + Butanol + Cyclohexane Solvent Mixtures. J. Chem. Eng. Data 1998, 43, 1062-1064.

(18) Acree, W. E., J r.; Zvaigzne, A. I.; Tucker, S. A. Thermochemical Investigations of Hydrogen-Bonded Solutions. Development of a Predictive Equation for the Solubility of Anthracene in Binary Hydrocarbon + Alcohol Mixtures Based upon Mobile Order Theory. Fluid Phase Equilib. 1994, 92, 233-253.

(19) Powell, J. R.; Miller, B. J .; Acree, W. E., J r. Solubility of Anthracene in Binary Alcohol + 1,4-Dioxane Solvent Mixtures. J. Chem. Eng. Data 1995, 40, 1124-1126.

(20) Zvaigzne, A. I.; Acree, W. E., J r. Solubility of Anthracene in Binary Alkane + 2-Butanol Solvent Mixtures. J. Chem. Eng. Data 1994, 39, 114-116.

(21) Zvaigzne, A. I.; Teng, I.-L.; Martinez, E.; Trejo, I .; Acree, W. E. $\mathrm{J}$ r. Solubility of Anthracene in Binary Alkane + 1-Propanol and Alkane+ 1-Butanol Solvent Mixtures. J . Chem. Eng. Data 1993, 38, 389-392.

(22) Zvaigzne, A. I.; Wolfe, J .; Acree, W. E., J r. Solubility of Anthracene in Binary Alkane + 2-Methyl-1-propanol Solvent Mixtures. J . Chem. Eng. Data 1994, 39, 541-543.

(23) Procyk, A. D.; Bissell, M. Street, K. W. J r.: Acree, W. E., J r. Solubility in Binary Solvent Systems: 8: Estimation of Binary Alkane plus p-Dioxane Solvent Nonideality from Measured Anthracene Solubilities. J. Pharm. Sci. 1987, 76, 621-625.

(24) Pribyla, K.J .; Acree, W. E.,, J r. Solubility of Anthracene in Ternary Dibutyl Ether + Alcohol + Cyclohexane Solvent Mixtures. J. Chem. Eng. Data 1999, 44, 1020-1023.

(25) Pribyla K. J.; Acree, W. E.,J r. Solubility of Anthracene in Ternary Dibutyl Ether + Alcohol + Heptane Solvent Mixtures. J. Chem. Eng. Data 1999, 44, 1259-1261.

(26) Pribyla, K.J .; Spurgin, M. A.; Chuca, I.; Acree, W. E., J r. Solubility of Anthracene in Ternary Dibutyl Ether + Alcohol + 2,2,4-Trimethyl pentane Solvent Mixtures at 298.15 K.J . Chem. Eng. Data 1999, 44, 1265-1268.

(27) Hansen, H. K.; Riverol, C.; Alvarez, E.; Acree, W. E., J r. Solubilities of Anthracene, Fluoranthene and Pyrene in Organic Solvents. Comparison of Calculated Values Using UNIFAC and Modified UNIFAC (Dortmund) with Experimental Data and Values Using Mobile Order Theory. Can. J . Chem. Eng., submitted for publication.

Received for review March 13, 2000. Accepted May 19, 2000. 